\title{
Addition of Integers in Mixed Radix System
}

\author{
H. B. Kekre \\ Senior Professor, Department \\ of Computer Science \\ Mukesh Patel School of \\ Technology Management \& \\ Engineering \\ Mumbai, India
}

\author{
V. R. Lakshmi Gorty \\ Associate Professor \\ Department of Computer \\ Science \\ Mukesh Patel School of \\ Technology Management \& \\ Engineering \\ Mumbai, India
}

\begin{abstract}
In this paper, two integers with two radices and the sum of the integers in the mixed radix form is represented. In the second part of the paper, more than two radices are taken and obtained the sum of the integers. Also a MATLAB code is generated to obtain the mixed radix form of the number. The extension of the same procedure is done for $n$-integers and $n$ radices. The application of the mixed radix system is used in signal, image processing for data compression and many other computer applications.
\end{abstract}

\section{Keywords}

Mixed radix system, integers, radices.

\section{INTRODUCTION}

Let $N$ be any integer consisting of radix $r$,

then $N=m_{n-1} r^{n-1}+\ldots+m_{4} r^{4}+m_{3} r^{3}+m_{2} r^{2}+m_{1} r+m_{0}$.

In case of mixed radix form general representation is:

$N=m_{n-1} r_{n-1} \ldots r_{3} r_{2} r_{1}+\ldots+r_{4} r_{3} r_{2} r_{1} m_{4}+r_{3} r_{2} r_{1} m_{3}+r_{2} r_{1} m_{2}+r_{1} m_{1}+m_{0}$,

where $r_{1}, r_{2}, r_{3}, \ldots, r_{n-1}$ are different radices and when $r_{1}=r_{2}=r_{3}=\ldots=r_{n-1}=r$, then mixed radix reduces to fixed radix system. Thus mixed radix is general and fixed radix is a special case of mixed radix system. $N$ in case of a fixed radix can be decomposed by dividing $N$ by $r$ successively to get coefficients $m_{0}, m_{1}, m_{2}, \ldots, m_{n-1}$ as remainders. In case of mixed radix $N$ can be decomposed by dividing $N$ by $r_{1}$ to obtain $m_{0}$ as a remainder and quotient can then be divided by $r_{2}$ to obtain $m_{1}$ as remainder. The process can be continued till $m_{n-1}$ is obtained. Thus $n$-tuple $\left(m_{n-1}, \ldots, m_{2}, m_{1}, m_{0}\right)$ is obtained representing number $N$.

From [1] results of mixed radix system are compared given by Kekre et al. In [2] work represented an algorithm which partitions a large mixed radix conversion problem into mixed radix problems of smaller size. The author explains the mixed radix representation of a number with respect to the radix vector in [3]. The theory presented by [4] was based on Reed-Muller expansions over Galois field arithmetic. The work explained real-life examples focusing on cryptographic circuits.

In [5], authors' comments on an arithmetic free parallel Mixed-Radix conversion algorithm. In [6], the work describes the magnitude comparison, sign detection and overflow detection for the residue number system was facilitated by converting the residue representations into the associated Mixed-Radix number system. The Chinese remainder theorem (CRT) and Mixed-Radix conversion (MRC) theorems were used to convert a residue number to its binary correspondence for a given moduli set. A new MixedRadix CRT possessed both the advantages of the CRT and the $\mathrm{MRC}$, the efficiency of making modulo comparison in [7].

A new method was proposed for converting residue integers into a mixed radix notation. The method based upon a modified formulation of the Chinese Remainder Theorem and look-up table implementations was explained in [8]. In [9] applications have been shown for security using Mixed Radix design flow. In [10] the author explains modulo $m_{i}$ addition time is independent of the word length of operands.

\section{MIXED RADIX SYSTEM}

Considering $N_{1}$ and $N_{2}$ as any integers consisting of radices $r_{1}, r_{2}$, then general representation of any integer is given below as:

$$
\begin{aligned}
& N_{1}=r_{2} r_{1} m_{2}+r_{1} m_{1}+m_{0} \\
& N_{2}=r_{2} r_{1} n_{2}+r_{1} n_{1}+n_{0} \\
& N_{1}+N_{2}=r_{2} \cdot r_{1}\left(m_{2}+n_{2}\right)+r_{1}\left(m_{1}+n_{1}\right)+\left(m_{0}+n_{0}\right) \\
& N_{1}+N_{2}-\left(m_{0}+n_{0}\right)=r_{2} \cdot r_{1}\left(m_{2}+n_{2}\right)+r_{1}\left(m_{1}+n_{1}\right) \\
& \left(N_{1}+N_{2}\right)-\left(m_{0}+n_{0}\right)=r_{1}\left[r_{2} \cdot\left(m_{2}+n_{2}\right)+\left(m_{1}+n_{1}\right)\right] \\
& \frac{\left(N_{1}+N_{2}\right)-\left(m_{0}+n_{0}\right)}{r_{1}}=r_{2} \cdot\left(m_{2}+n_{2}\right)+\left(m_{1}+n_{1}\right) \\
& \frac{\left(N_{1}+N_{2}\right)-\left(m_{0}+n_{0}\right)}{r_{1}}-\left(m_{1}+n_{1}\right)=r_{2} \cdot\left(m_{2}+n_{2}\right) \\
& \frac{\left(N_{1}+N_{2}\right)-\left(m_{0}+n_{0}\right)}{r_{1} r_{2}}-\frac{\left(m_{1}+n_{1}\right)}{r_{2}}=\left(m_{2}+n_{2}\right) \\
& \frac{\left(N_{1}+N_{2}\right)-\left(m_{0}+n_{0}\right)}{r_{1} r_{2}}-\frac{\left(m_{1}+n_{1}\right)}{r_{2}}-\left(m_{2}+n_{2}\right)=0 .
\end{aligned}
$$

In Mixed Radix the combination can be

$$
\begin{aligned}
& r_{1}=2 ; r_{2}=3 \text { then } m_{1}=0,1 ; m_{2}=0,1,2 \\
& r_{1}=2 ; r_{2}=5 \text { then } m_{1}=0,1,2 ; m_{2}=0,1,2,3 \\
& r_{1}=2 ; r_{2}=7 \text { then } m_{1}=0,1,2,3 ; m_{2}=0,1,2,3,4
\end{aligned}
$$


and so on.

$r_{1}=2,3,5,7,11,13, \ldots$

$r_{2}=3,5,7,11,13, \ldots$

$N_{1}=$ even or odd.

$N_{2}=$ even or odd.

If $N_{1}=$ even; then value of $m_{0}=0$ and if $N_{1}=$ odd; then value of $m_{0}=1$.

If $N_{2}=$ even; then value of $n_{0}=0$ and if $N_{2}=$ odd; then value of $n_{0}=1$.

Thus $m_{0}+n_{0}$ will take either 0,1 or 2 depending on even or odd number.

\section{TYPES OF MIXED RADIX FORM:}

\subsection{Case 1: If $N_{1}=$ even; $N_{2}=$ even.}

If $N_{1}=$ even; then value of $m_{0}=0, N_{2}=$ even;

then value of $n_{0}=0$.

(i) If $m_{0}+n_{0}=0$. If $m_{1}+n_{1}=0 . m_{2}+n_{2}$ will be equal to $\frac{\left(N_{1}+N_{2}\right)}{r_{1} r_{2}}$, which is quite obvious case.

(ii) If $m_{0}+n_{0}=0 ; m_{0}=0, n_{0}=0 \cdot m_{1}+n_{1}$ take values $1,2,3, \ldots,\left\{\left(r_{1}-1\right)+\left(r_{1}-1\right)=2\left(r_{1}-1\right)\right\}$

$m_{1}+n_{1}=1 ; m_{1}=1 ; n_{1}=0$ or $m_{1}=0 ; n_{1}=1 . m_{2}+n_{2}$ takes

$\frac{\left(N_{1}+N_{2}\right)}{r_{1} r_{2}}-\frac{1}{r_{2}} \cdot m_{2}+n_{2}$ can take values

$0,1,2,3, \ldots,\left\{\left(r_{1} r_{2}-1\right)+\left(r_{1} r_{2}-1\right)\right\}=2\left(r_{1} r_{2}-1\right)$. For

$N_{1}=$ even; $N_{2}=$ even, the output of results with all possible

values of $m_{1}, m_{2}, n_{1}, n_{2}$ are considered under the criteria of

Mixed Radix applicability with the help of a code generated in MATLAB and obtained the possible values of $N_{1}$ and $N_{2}$,

along with $\mathrm{N}_{1}+\mathrm{N}_{2}$.

$\% \mathrm{~N} 1$ is even and $\mathrm{N} 2$ is even

syms r1 r2 m1 m2 n1 n2 m0 n0 N1 N2;

$\mathrm{x}=1$;

for $\mathrm{m} 1=0: 1:(\mathrm{r} 1-1)$

for $\mathrm{n} 1=0: 1:(\mathrm{r} 1-1)$

for $\mathrm{m} 2=0: 1:(\mathrm{r} 2-1)$

for $\mathrm{n} 2=0: 1:(\mathrm{r} 2-1)$

$\mathrm{n} 0=0$

$\mathrm{m} 0=0$;

$\mathrm{N} 1=\mathrm{r} 1 . * \mathrm{r} 2 . * \mathrm{~m} 2+\mathrm{r} 1 . * \mathrm{~m} 1+\mathrm{m} 0$

$\mathrm{N} 2=\mathrm{r} 1 . *_{\mathrm{r}} 2 \cdot *_{\mathrm{n}} 2+\mathrm{r} 1 \cdot *_{\mathrm{n}} 1+\mathrm{n} 0$;

$\begin{array}{lllll}\text { fprintf('In } & \mathrm{m} 2 & \mathrm{n} 2 & \mathrm{~N} 1 & \mathrm{~N} 2\end{array}$

$\mathrm{N} 1+\mathrm{N} 2\lfloor\mathrm{n}$ ')

fprintf('In \%3.4f $\quad \% 3.4 \mathrm{f} \quad \% 3.4 \mathrm{f} \quad \% 3.4 \mathrm{f} \quad \% 3.4 \mathrm{f} \backslash \mathrm{n}$ ',m2,n2,

$\mathrm{N} 1, \mathrm{~N} 2, \mathrm{~N} 1+\mathrm{N} 2)$

$\mathrm{x}=\mathrm{x}+1$;

end

end

end end

3.2 Case 2: If $N_{1}=$ even; $N_{2}=$ odd.

If $N_{1}=$ even; then value of $m_{0}=0, N_{2}=$ odd;

then value of $n_{0}=1$.

(i) If $m_{0}+n_{0}=1$. Substituting in

$$
\frac{\left(N_{1}+N_{2}\right)-\left(m_{0}+n_{0}\right)}{r_{1} r_{2}}-\frac{\left(m_{1}+n_{1}\right)}{r_{2}}-\left(m_{2}+n_{2}\right)=0,
$$

with $m_{1}+n_{1}=0 . m_{2}+n_{2}$ will be equal to $\frac{\left(N_{1}+N_{2}\right)-1}{r_{1} r_{2}}$, which is quite obvious case.

(ii) If $m_{0}+n_{0}=1 ; m_{0}=0$ and $n_{0}=1$.

$m_{1}+n_{1}$ can take values $0,1,2,3, \ldots,\left(r_{1}-1\right)+\left(r_{1}-1\right)=2\left(r_{1}-1\right)$.

$m_{2}+n_{2}$ can take values

$0,1,2,3, \ldots,\left\{\left(r_{1} r_{2}-1\right)+\left(r_{1} r_{2}-1\right)\right\}=2\left(r_{1} r_{2}-1\right)$. For

$N_{1}=$ even; $N_{2}=$ odd, the output of results with all possible

values of $m_{1}, m_{2}, n_{1}, n_{2}$ are considered under the criteria of

Mixed Radix applicability with the help of a code generated in MATLAB and obtained the possible values of $N_{1}$ and $N_{2}$,

along with $N_{1}+N_{2}$.

$\% \mathrm{~N} 1$ is even and $\mathrm{N} 2$ is odd

syms r1 r2 m1 m2 n1 n2 m0 n0 N1 N2;

$\mathrm{x}=1$;

for $\mathrm{m} 1=0: 1:(\mathrm{r} 1-1)$

for $\mathrm{n} 1=0: 1:(\mathrm{r} 1-1)$

$\mathrm{n} 0=1$;

for $\mathrm{m} 2=0: 1:(\mathrm{r} 2-1)$

for $\mathrm{n} 2=0: 1:(\mathrm{r} 2-1)$

$\mathrm{n} 0=1$;

$\mathrm{m} 0=0$;

$\mathrm{N} 1=\mathrm{r} 1 . * \mathrm{r} 2 . * \mathrm{~m} 2+\mathrm{r} 1 \cdot * \mathrm{~m} 1+\mathrm{m} 0 ;$

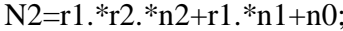

$\begin{array}{llllll}\text { fprintf('ไn } & \mathrm{m} 2 & \mathrm{~m} 1 & \mathrm{~m} 0 & \mathrm{~N} 2 & \mathrm{~N} 1+\mathrm{N} 2 \backslash \mathrm{n} \text { ') }\end{array}$

fprintf('In $\% 3.4 \mathrm{f} \quad \% 3.4 \mathrm{f} \quad \% 3.4 \mathrm{f} \quad \% 3.4 \mathrm{f} \quad \% 3.4 \mathrm{f}$ \%3.4f $\quad \% 3.4 \mathrm{f} \quad \% 3.4 \mathrm{f} \quad \% 3.4 \mathrm{f} \backslash \mathrm{n}, \mathrm{m} 2, \mathrm{~m} 1, \mathrm{~m} 0, \mathrm{n} 2, \mathrm{n} 1, \mathrm{n} 0$, $\mathrm{N} 1, \mathrm{~N} 2, \mathrm{~N} 1+\mathrm{N} 2)$

$\mathrm{x}=\mathrm{x}+1$;

end

end

end

end

3.3 Case 3: If $N_{1}=$ odd; $N_{2}=$ even.

If $N_{1}=$ odd; then value of $m_{0}=1, N_{2}=$ even;

then value of $n_{0}=0$. 
(i) If $m_{0}+n_{0}=1$. Substituting in

$$
\frac{\left(N_{1}+N_{2}\right)-\left(m_{0}+n_{0}\right)}{r_{1} r_{2}}-\frac{\left(m_{1}+n_{1}\right)}{r_{2}}-\left(m_{2}+n_{2}\right)=0,
$$

with $m_{1}+n_{1}=0 . m_{2}+n_{2}$ will be equal to $\frac{\left(N_{1}+N_{2}\right)-1}{r_{1} r_{2}}$, which is quite obvious case.

(ii) If $m_{0}+n_{0}=1 ; m_{0}=1$ and $n_{0}=0$.

$m_{1}+n_{1}$ can take values $0,1,2,3, \ldots,\left(r_{1}-1\right)+\left(r_{1}-1\right)=2\left(r_{1}-1\right)$.

$m_{2}+n_{2}$ can take values $0,1,2,3, \ldots,\left\{\left(r_{1} r_{2}-1\right)+\left(r_{1} r_{2}-1\right)\right\}=2\left(r_{1} r_{2}-1\right)$.

For $N_{1}=$ odd; $N_{2}=$ even, the output of results with all possible values of $m_{1}, m_{2}, n_{1}, n_{2}$ are considered under the criteria of Mixed Radix applicability with the help of a code generated in MATLAB and obtained the possible values of $N_{1}$ and $N_{2}$, along with $N_{1}+N_{2}$.

$\% \mathrm{~N} 1$ is odd and $\mathrm{N} 2$ is even

syms r1 r2 m1 m2 n1 n2 m0 n0 N1 N2;

$\mathrm{x}=1$;

for $\mathrm{m} 1=0: 1:(\mathrm{r} 1-1)$

for $\mathrm{n} 1=0: 1:(\mathrm{r} 1-1)$

for $\mathrm{m} 2=0: 1:(\mathrm{r} 2-1)$

for $\mathrm{n} 2=0: 1:(\mathrm{r} 2-1)$

$\mathrm{n} 0=0$;

$\mathrm{m} 0=1$;

$\mathrm{N} 1=\mathrm{r} 1 . * \mathrm{r} 2 . * \mathrm{~m} 2+\mathrm{r} 1 . * \mathrm{~m} 1+\mathrm{m} 0$

$\mathrm{N} 2=\mathrm{r} 1 . * \mathrm{r} 2 . *_{\mathrm{n}} 2+\mathrm{r} 1 \cdot *_{\mathrm{n}} 1+\mathrm{n} 0$;

\begin{tabular}{llrrrrr} 
fprintf('In & $\mathrm{m} 2$ & \multicolumn{2}{c}{$\mathrm{m} 1$} & \multicolumn{2}{c}{$\mathrm{m} 0$} & $\mathrm{n} 2$ \\
$\mathrm{n} 1$ & $\mathrm{n} 0$ & $\mathrm{~N} 1$ & $\mathrm{~N} 2$ & $\mathrm{~N} 1+\mathrm{N} 2 \backslash \mathrm{n}$ ') \\
fprintf('In $\% 3.4 \mathrm{f}$ & $\% 3.4 \mathrm{f}$ & $\% 3.4 \mathrm{f}$ & $\% 3.4 \mathrm{f}$ & $\% 3.4 \mathrm{f}$ \\
$\% 3.4 \mathrm{f}$ & $\% 3.4 \mathrm{f}$ & $\% 3.4 \mathrm{f}$ & \multicolumn{2}{c}{$\% 3.4 \mathrm{fln}, \mathrm{m} 2, \mathrm{~m} 1, \mathrm{~m} 0, \mathrm{n} 2, \mathrm{n} 1, \mathrm{n} 0}$,
\end{tabular}

$\mathrm{N} 1, \mathrm{~N} 2, \mathrm{~N} 1+\mathrm{N} 2)$

$\mathrm{x}=\mathrm{x}+1$;

end

end

end

end

3.4 Case 4: If $N_{1}=$ odd; $N_{2}=$ odd.

If $N_{1}=$ odd; then value of $m_{0}=1, N_{2}=$ odd;

then value of $n_{0}=1$.

(i) If $m_{0}+n_{0}=2$. Substituting in

$$
\frac{\left(N_{1}+N_{2}\right)-\left(m_{0}+n_{0}\right)}{r_{1} r_{2}}-\frac{\left(m_{1}+n_{1}\right)}{r_{2}}-\left(m_{2}+n_{2}\right)=0,
$$

with $m_{1}+n_{1}=0 . m_{2}+n_{2}$ will be equal to $\frac{\left(N_{1}+N_{2}\right)-2}{r_{1} r_{2}}$, which is quite obvious case. (ii) If $m_{0}+n_{0}=2 ; m_{0}=1 ; n_{0}=1$.

$m_{1}+n_{1}$ can take values $0,1,2,3, \ldots,\left(r_{1}-1\right)+\left(r_{1}-1\right)=2\left(r_{1}-1\right)$.

$m_{2}+n_{2}$ can take values

$0,1,2,3, \ldots,\left\{\left(r_{1} r_{2}-1\right)+\left(r_{1} r_{2}-1\right)\right\}=2\left(r_{1} r_{2}-1\right)$.

For $N_{1}=$ odd; $N_{2}=$ odd, the output of results with all possible values of $m_{1}, m_{2}, n_{1}, n_{2}$ are considered under the criteria of Mixed Radix applicability with the help of a code generated in MATLAB and obtained the possible values of $N_{1}$ and $N_{2}$, along with $N_{1}+N_{2}$.

$\% \mathrm{~N} 1$ is odd and N2 is odd

syms r1 r2 m1 m2 n1 n2 m0 n0 N1 N2;

$\mathrm{x}=1$;

for $\mathrm{ml}=0: 1:(\mathrm{r} 1-1)$

for $\mathrm{n} 1=0: 1:(\mathrm{r} 1-1)$

for $\mathrm{m} 2=0: 1:(\mathrm{r} 2-1)$

for $\mathrm{n} 2=0: 1:(\mathrm{r} 2-1)$

$\mathrm{n} 0=1$;

$\mathrm{m} 0=1$

$\mathrm{N} 1=\mathrm{r} 1 . * \mathrm{r} 2 . * \mathrm{~m} 2+\mathrm{r} 1 . * \mathrm{~m} 1+\mathrm{m} 0 ;$

$\mathrm{N} 2=\mathrm{r} 1 \cdot *_{\mathrm{r} 2} \cdot{ }^{*} \mathrm{n} 2+\mathrm{r} 1 \cdot *_{\mathrm{n}} 1+\mathrm{n} 0$

fprintf(') $\mathrm{m} 2$

$\mathrm{N} 1 \mathrm{~m}^{\mathrm{N} 2} \stackrel{\mathrm{m} 0}{\left.\mathrm{~N} 1+\mathrm{N} 2 \backslash \mathrm{n}^{\prime}\right)}{ }^{\mathrm{n} 2}$

fprintf('In \%3.4f $\quad \% 3.4 \mathrm{f} \quad \% 3.4 \mathrm{f} \quad \% 3.4 \mathrm{f} \quad \% 3.4 \mathrm{f}$ \%3.4f $\quad \% 3.4 \mathrm{f} \quad \% 3.4 \mathrm{f} \quad \% 3.4 \mathrm{f} \backslash \mathrm{n}^{\prime}, \mathrm{m} 2, \mathrm{~m} 1, \mathrm{~m} 0, \mathrm{n} 2, \mathrm{n} 1, \mathrm{n} 0$, $\mathrm{N} 1, \mathrm{~N} 2, \mathrm{~N} 1+\mathrm{N} 2$ )

$\mathrm{x}=\mathrm{x}+1$

end

end

end

end

\subsection{Example 1:}

Consider $r_{1}=2 ; r_{2}=3$

$$
\begin{aligned}
& 14=r_{2} r_{1} m_{2}+r_{1} m_{1}+m_{0}=3 \cdot 2 \cdot m_{2}+2 m_{1}+m_{0} \\
& 9=r_{2} r_{1} n_{2}+r_{1} n_{1}+n_{0}=3 \cdot 2 \cdot n_{2}+2 \cdot n_{1}+n_{0} \\
& 23=3 \cdot 2 \cdot\left(m_{2}+n_{2}\right)+2 \cdot\left(m_{1}+n_{1}\right)+\left(m_{0}+n_{0}\right) \\
& 23-\left(m_{0}+n_{0}\right)=3 \cdot 2 \cdot\left(m_{2}+n_{2}\right)+2 \cdot\left(m_{1}+n_{1}\right) \\
& 23-\left(m_{0}+n_{0}\right)=2\left[3 \cdot\left(m_{2}+n_{2}\right)+\left(m_{1}+n_{1}\right)\right] . \\
& \frac{23-\left(m_{0}+n_{0}\right)}{2}=\left[3 \cdot\left(m_{2}+n_{2}\right)+\left(m_{1}+n_{1}\right)\right]
\end{aligned}
$$

If $\left(m_{0}+n_{0}\right)=1$;

$\left(m_{2}+n_{2}\right)=3$

$\left(m_{1}+n_{1}\right)=2$ 
Let $m_{0}=0$ and $n_{0}=1$ in equation (4) and equation (5), an even number and odd number is obtained respectively.

Since $r_{1}=2$ so value of $m_{1}=1$ and $n_{1}=1$.

$14=3 \cdot 2 \cdot m_{2}+2 \cdot 1+0$.

$m_{2}=2$. Thus $n_{2}=1$.

Thus values of $m_{0}=0 ; m_{1}=1 ; m_{2}=2$.

Thus values of $n_{0}=1 ; n_{1}=1 ; n_{2}=1$.

\section{ADDITION OF THREE NATURAL NUMBERS WITH MIXED RADIX:}

$N_{1}=r_{2} r_{1} m_{2}+r_{1} m_{1}+m_{0}$

$N_{2}=r_{2} r_{1} n_{2}+r_{1} n_{1}+n_{0}$

$N_{3}=r_{2} r_{1} p_{2}+r_{1} p_{1}+p_{0}$

$N_{1}+N_{2}+N_{3}=r_{2} \cdot r_{1}\left(m_{2}+n_{2}+p_{2}\right)$

$$
+r_{1}\left(m_{1}+n_{1}+p_{1}\right)+\left(m_{0}+n_{0}+p_{0}\right)
$$

$N_{1}+N_{2}+N_{3}-\left(m_{0}+n_{0}+p_{0}\right)=r_{2} \cdot r_{1}\left(m_{2}+n_{2}+p_{2}\right)+r_{1}\left(m_{1}+n_{1}+p_{1}\right)$

$\left(N_{1}+N_{2}+N_{3}\right)-\left(m_{0}+n_{0}+p_{0}\right)=r_{1}\left[r_{2} \cdot\left(m_{2}+n_{2}+p_{2}\right)+\left(m_{1}+n_{1}+p_{1}\right)\right]$

$\frac{\left(N_{1}+N_{2}+N_{3}\right)-\left(m_{0}+n_{0}+p_{0}\right)}{r_{1}}=r_{2} \cdot\left(m_{2}+n_{2}+p_{2}\right)+\left(m_{1}+n_{1}+p_{1}\right)$

$\frac{\left(N_{1}+N_{2}+N_{3}\right)-\left(m_{0}+n_{0}+p_{0}\right)}{r_{1}}-\left(m_{1}+n_{1}+p_{1}\right)=r_{2} \cdot\left(m_{2}+n_{2}+p_{2}\right)$

$\frac{\left(N_{1}+N_{2}+N_{3}\right)-\left(m_{0}+n_{0}+p_{0}\right)}{r_{1} r_{2}}-\frac{\left(m_{1}+n_{1}+p_{1}\right)}{r_{2}}=\left(m_{2}+n_{2}+p_{2}\right)$

$\frac{\left(N_{1}+N_{2}+N_{3}\right)-\left(m_{0}+n_{0}+p_{0}\right)}{r_{1} r_{2}}-\frac{\left(m_{1}+n_{1}+p_{1}\right)}{r_{2}}-\left(m_{2}+n_{2}+p_{2}\right)=0$

In the similar manner, if $N_{1}=$ even; $N_{2}=$ even; $N_{3}=$ even.

If $N_{1}=$ even; then value of $m_{0}=0, N_{2}=$ even;

then value of $n_{0}=0 ; N_{3}=$ even,

then value of $p_{0}=0$.

If $m_{0}+n_{0}+p_{0}=0$. If $\left(m_{1}+n_{1}+p_{1}\right)=0 .\left(m_{2}+n_{2}+p_{2}\right)$

will be equal to $\frac{\left(N_{1}+N_{2}+N_{3}\right)}{r_{1} r_{2}}$, which is quite obvious

case.

If $m_{0}+n_{0}+p_{0}=0 ; m_{0}=0, n_{0}=0 ; p_{0}=0$.

$m_{1}+n_{1}+p_{1}$ take values $1,2,3, \ldots,\left\{\left(r_{1}-1\right)+\left(r_{1}-1\right)=2\left(r_{1}-1\right)\right\}$;

$m_{1}+n_{1}+p_{1}=1$

$m_{1}=1 ; n_{1}=0 ; p_{1}=0$

or $m_{1}=0 ; n_{1}=1, p_{1}=0$

or $m_{1}=0 ; n_{1}=0, p_{1}=1$

$\left(m_{2}+n_{2}+p_{2}\right)$ takes $\frac{\left(N_{1}+N_{2}\right)}{r_{1} r_{2}}-\frac{1}{r_{2}}$.

$m_{2}+n_{2}$ can take values

$0,1,2,3, \ldots,\left\{\left(r_{1} r_{2}-1\right)+\left(r_{1} r_{2}-1\right)\right\}=2\left(r_{1} r_{2}-1\right)$.

For $N_{1}=$ even; $N_{2}=$ even, $N_{3}=$ even; the output of results

with all possible values of $m_{1}, m_{2}, n_{1}, n_{2}, p_{1}, p_{2}$ are considered under the criteria of Mixed Radix applicability with the help of a code generated in MATLAB and obtained the possible values of $N_{1}, N_{2}$ and $N_{3}$, along with $N_{1}+N_{2}+N_{3}$.

$\% \mathrm{~N} 1$ is even, $\mathrm{N} 2$ is even and $\mathrm{N} 3$ is even syms $\mathrm{r} 1 \mathrm{r} 2 \mathrm{~m} 1 \mathrm{~m} 2 \mathrm{n} 1 \mathrm{n} 2 \mathrm{~m} 0 \mathrm{n} 0 \mathrm{p} 1 \mathrm{p} 2 \mathrm{p} 0 \mathrm{~N} 1 \mathrm{~N} 2 \mathrm{~N} 3$; $\mathrm{x}=1$; for $\mathrm{m} 1=0: 1:(\mathrm{r} 1-1)$

for $\mathrm{n} 1=0: 1:(\mathrm{r} 1-1)$

for $\mathrm{p} 1=0: 1:(\mathrm{r} 1-1)$

for $\mathrm{m} 2=0: 1:(\mathrm{r} 2-1)$

for $\mathrm{n} 2=0: 1:(\mathrm{r} 2-1)$

for $\mathrm{p} 2=0: 1:(\mathrm{r} 2-1)$

$\mathrm{n} 0=0$;

$\mathrm{m} 0=0$;

$\mathrm{p} 0=0$;

$\mathrm{N} 1=\mathrm{r} 1 . * \mathrm{r} 2 . * \mathrm{~m} 2+\mathrm{r} 1 . * \mathrm{~m} 1+\mathrm{m} 0$;

$\mathrm{N} 2=\mathrm{r} 1 * *_{\mathrm{r}} 2 * \mathrm{n} 2+\mathrm{r} 1 * *_{\mathrm{n}} 1+\mathrm{n} 0$

$\mathrm{N} 3=\mathrm{r} 1 \cdot * \mathrm{r} 2 \cdot{ }^{*} \mathrm{p} 2+\mathrm{r} 1 \cdot * \mathrm{p} 1+\mathrm{p} 0$;

fprintf('In $\mathrm{m} 2$

n1 n0

$\mathrm{N} 1-\mathrm{N} 2$

\%3.4f $\quad \% 3.4 \mathrm{f} \quad \% 3.4 \mathrm{f} \quad \% 3.4 \mathrm{f} \quad \% 3.4 \mathrm{f} \quad \% 3.4 \mathrm{f}$

\%3.4f \%3.4fln',m2,m1,m0,n2,n1, n0, p0,p1,p2,N1, N2,

$\mathrm{N} 3, \mathrm{~N} 1+\mathrm{N} 2+\mathrm{N} 3)$

$\mathrm{x}=\mathrm{x}+1$;

end
end
end
end

end

All other possible ways in which the mixed radix addition can be in the following manners:

$$
\begin{aligned}
& N_{1}=\text { even } ; N_{2}=\text { even, } N_{3}=\text { odd } \\
& N_{1}=\text { even } ; N_{2}=\text { odd }, N_{3}=\text { odd } \\
& N_{1}=\text { odd } ; N_{2}=\text { even }, N_{3}=\text { odd } \\
& N_{1}=\text { odd } ; N_{2}=\text { even, } N_{3}=\text { even } \\
& N_{1}=\text { odd } ; N_{2}=\text { odd }, N_{3}=\text { odd } \\
& N_{1}=\text { even } ; N_{2}=\text { odd }, N_{3}=\text { even } \\
& N_{1}=\text { odd } ; N_{2}=\text { odd }, N_{3}=\text { even }
\end{aligned}
$$

A code is generated in the similar manner and obtained all values for the initial radices and values of the sum of the possible integers in the similar manner.

These representations can be extended to $n$-numbers and find the possible sum of these numbers by considering the possible values of $a_{2}, a_{1}, a_{0}, b_{2}, b_{1}, b_{0}, \ldots$ in the same way.

$$
\begin{aligned}
& N_{1}=r_{2} r_{1} a_{2}+r_{1} a_{1}+a_{0} \\
& N_{2}=r_{2} r_{1} b_{2}+r_{1} b_{1}+b_{0} \\
& N_{3}=r_{2} r_{1} c_{2}+r_{1} c_{1}+c_{0} \\
& N_{4}=r_{2} r_{1} d_{2}+r_{1} d_{1}+d_{0} \\
& \cdot \\
& \cdot \\
& N_{n}=r_{2} r_{1} n_{2}+r_{1} n_{1}+n_{0}
\end{aligned}
$$

Considering the numbers in more than three radices:

$$
\begin{aligned}
& N_{1}=r_{4} r_{3} r_{2} r_{1} m_{4}+r_{3} r_{2} r_{1} m_{3}+r_{2} r_{1} m_{2}+r_{1} m_{1}+m_{0} \\
& N_{2}=r_{4} r_{3} r_{2} r_{1} n_{4}+r_{3} r_{2} r_{1} n_{3}+r_{2} r_{1} n_{2}+r_{1} n_{1}+n_{0}
\end{aligned}
$$




$$
\begin{aligned}
& N_{1}+N_{2}=r_{4} r_{3} r_{2} r_{1}\left(m_{4}+n_{4}\right) \\
& +r_{3} r_{2} r_{1}\left(m_{3}+n_{3}\right) \\
& +r_{2} \cdot r_{1}\left(m_{2}+n_{2}\right) \\
& +r_{1}\left(m_{1}+n_{1}\right)+\left(m_{0}+n_{0}\right) \\
& N_{1}+N_{2}-\left(m_{0}+n_{0}\right)=r_{4} r_{3} r_{2} r_{1}\left(m_{4}+n_{4}\right)+r_{3} r_{2} r_{1}\left(m_{3}+n_{3}\right)+r_{2} . r_{1}\left(m_{2}+n_{2}\right)+r_{1}\left(m_{1}+n_{1}\right) \\
& \left(N_{1}+N_{2}\right)-\left(m_{0}+n_{0}\right)=r_{1}\left[r_{4} r_{3} r_{2}\left(m_{4}+n_{4}\right)+r_{3} r_{2}\left(m_{3}+n_{3}\right)+r_{2}\left(m_{2}+n_{2}\right)+\left(m_{1}+n_{1}\right)\right] \\
& \frac{\left(N_{1}+N_{2}\right)-\left(m_{0}+n_{0}\right)}{r_{1}}=r_{4} r_{3} r_{2}\left(m_{4}+n_{4}\right)+r_{3} r_{2}\left(m_{3}+n_{3}\right)+r_{2}\left(m_{2}+n_{2}\right)+\left(m_{1}+n_{1}\right) \\
& \frac{\left(N_{1}+N_{2}\right)-\left(m_{0}+n_{0}\right)}{r_{1}}-\left(m_{1}+n_{1}\right)=r_{4} r_{3} r_{2}\left(m_{4}+n_{4}\right)+r_{3} r_{2}\left(m_{3}+n_{3}\right)+r_{2}\left(m_{2}+n_{2}\right) \\
& \frac{\left(N_{1}+N_{2}\right)-\left(m_{0}+n_{0}\right)}{r_{1} r_{2}}-\frac{\left(m_{1}+n_{1}\right)}{r_{2}} \\
& =r_{4} r_{3}\left(m_{4}+n_{4}\right)+r_{3}\left(m_{3}+n_{3}\right)+\left(m_{2}+n_{2}\right) \\
& \frac{\left(N_{1}+N_{2}\right)-\left(m_{0}+n_{0}\right)}{r_{1} r_{2}}-\frac{\left(m_{1}+n_{1}\right)}{r_{2}}-\left(m_{2}+n_{2}\right) \\
& =r_{4} r_{3}\left(m_{4}+n_{4}\right)+r_{3}\left(m_{3}+n_{3}\right) \\
& \frac{\left(N_{1}+N_{2}\right)-\left(m_{0}+n_{0}\right)}{r_{1} r_{2} r_{3} r_{4}}-\frac{\left(m_{1}+n_{1}\right)}{r_{4} r_{3} r_{2}}-\frac{\left(m_{2}+n_{2}\right)}{r_{4} r_{3}}-\frac{\left(m_{3}+n_{3}\right)}{r_{4}} \\
& =\left(m_{4}+n_{4}\right) \\
& \frac{\left(N_{1}+N_{2}\right)-\left(m_{0}+n_{0}\right)}{r_{1} r_{2} r_{3} r_{4}}-\frac{\left(m_{1}+n_{1}\right)}{r_{4} r_{3} r_{2}}-\frac{\left(m_{2}+n_{2}\right)}{r_{4} r_{3}}-\frac{\left(m_{3}+n_{3}\right)}{r_{4}}-\left(m_{4}+n_{4}\right)=0
\end{aligned}
$$

All other possible ways in which the mixed radix addition can be in the following manners:

$$
\begin{aligned}
& \% \mathrm{~N} 1 \text { is even, } \mathrm{N} 2 \text { is even; } \\
& \text { syms } \mathrm{r} 1 \mathrm{r} 2 \mathrm{~m} 1 \mathrm{~m} 2 \mathrm{n} 1 \mathrm{n} 2 \mathrm{~m} \\
& \mathrm{x}=1 \text {; } \\
& \text { for } \mathrm{m} 1=0: 1:(\mathrm{r} 1-1) \\
& \text { for } \mathrm{n} 1=0: 1:(\mathrm{r} 1-1) \\
& \text { for } \mathrm{m} 2=0: 1:(\mathrm{r} 2-1) \\
& \text { for } \mathrm{n} 2=0: 1:(\mathrm{r} 2-1) \\
& \text { for } \mathrm{m} 3=0: 1:(\mathrm{r} 3-1) \\
& \text { for } \mathrm{n} 3=0: 1:(\mathrm{r} 3-1) \\
& \text { for } \mathrm{m} 4=0: 1:(\mathrm{r} 4-1) \\
& \text { for } \mathrm{n} 4=0: 1:(\mathrm{r} 4-1) \\
& \mathrm{n} 0=0 ; \\
& \mathrm{m} 0=0 ;
\end{aligned}
$$$$
\text { syms r1 r2 m1 m2 n1 n2 m0 n0 N1 N2; }
$$

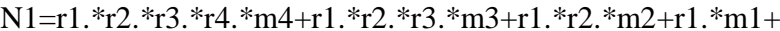
$\mathrm{m} 0$;

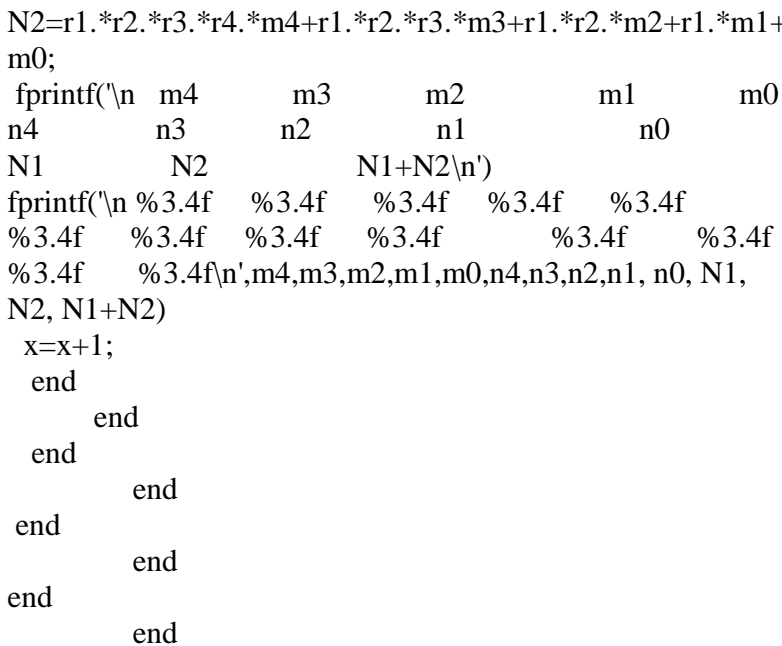

Thus in general the numbers can be calculated by mixed radix method for a given set of radices.

General representation is:

$N=m_{n-1} r_{n-1} \ldots r_{3} r_{2} r_{1}+\ldots+r_{4} r_{3} r_{2} r_{1} m_{4}+r_{3} r_{2} r_{1} m_{3}+r_{2} r_{1} m_{2}+r_{1} m_{1}+m_{0}$, where $r_{1}, r_{2}, r_{3}, \ldots, r_{n-1}$ are different radices.

\section{APPLICATION}

This method is very much useful in computer applications, in reading or sorting a particular number $N$ from the multidimensional array or sequence of numbers from its specified location. And if the distance is specified from an existing number, then by adding $N$ to the distance the next number can be obtained.

\section{CONCLUSION}

In this paper, a simple to understand and easily applied mixed radix system for addition of integers with known radices is developed. Initially a code is developed for two numbers and later developed not only for more than two numbers but also more than two radices. Here any number of integers with more than two radices can be added and obtained all the possible results of the addition of integers represented as a result of mixed radix system. Due to developed MATLAB code also the process becomes simpler and readily available to use.

\section{REFERENCE}

[1] Kekre, H. B., Sarode Tanuja, and Vig Rekha (2011). Unified Fast Algorithm for most commonly used Transforms using Mixed Radix and Kronecker product. IJCSIS, vol. 9, No.6, (194-202), (2011).

[2] Cetin, K., Koc, (1989). A fast Algorithm for MixedRadix Conversion in Residue Arithmetic. IEEE, Computer Society press, (October 2-4), (1989).

[3] Jörg Arndt, (2011). Matters Computational, Ideas, Algorithms, Source Code. Springer link.

[4] Ashur Rafiev, Andrey Mokhov, Frank P. Burns, Julian P. Murphy, Albert Koelmans, Alex Yakovlev. Mixed Radix Reed-Muller Expansions. IEEE Transactions on Computers. (vol. 61 no. 8), pp. 1189-1202, (Aug. 2012)

[5] Graham A. Jullien, and Antonio García, (1999). Comments on "An Arithmetic Free Parallel Mixed-Radix Conversion Algorithm". IEEE Trans. Circuits and Systems. VLSI Research Group.

[6] Israel K, (1993). Computer Arithmetic Algorithms. Prentice Hall PTR.

[7] Shaoqiang, Bi, Xilinx Inc., San Jose, C.A , Gross, W.J. The Mixed-Radix Chinese Remainder Theorem and Its Applications to Residue Comparison . Computers, IEEE Transactions on (Volume: 57, (12)), (1624-1632) (Dec. 2008).

[8] Barsi, F.and Pinotti, M. C. Time optimal mixed radix conversion for residue number applications. Mathematics \& Physical Sciences, Computer Journal (Vol. 37, Issue 10), (907-916), (1994).

[9] Rafiev, A. (September 2011). "Mixed Radix Design Flow for Security. Applications, Technical Report Series".

[10] Shugang .W., Number Conversions between RNS and Mixed Radix Number System Based on Modulo $\left(2^{\mathrm{p}}-1\right)$ Signed Digit Arithmetic, SBCCI'05, September 4-7, (2005). 